\title{
SCROTAL GANGRENE IN A NEWBORN BABY
}

\author{
BY \\ NICHOLAS ALDERS \\ From the Department of Obstetrics of the Royal Victoria Hospital, Bournemouth
}

(RECEIVED FOR PUBLICATION NOVEMBER 25, 1953)

Not more than 51 cases of gangrene occurring in the newborn have been reported so far, and only some 240 instances of idiopathic gangrene of the scrotum at any age are on record. A case of scrotal gangrene in a newborn baby is reported here because this condition must be extremely rare and because it illustrates the interesting fact that the newborn are liable to infection by common organisms of usually low pathogenicity with results similar to those caused in the adult by more virulent microorganisms.

\section{Case Report}

A primigravida, aged 21, was admitted to the Maternity Department on June 16, 1949. She was 36 weeks pregnant and the foetus presented by the vertex (L.O.A.). There were signs of pre-eclamptic toxaemia (blood-pressure $180 / 110 \mathrm{~mm}$. $\mathrm{Hg}$, oedema of the feet, ankles and abdominal wall, but no albuminuria). Her blood group was $\mathrm{A} \mathbf{R h}$ negative. The Wassermann reaction was negative. She was treated with rest in bed, sedatives and restriction of salt. Her condition improved and, on July 8, she was normally delivered of an apparently healthy male infant, weighing $7 \mathrm{lb}$. $12 \mathrm{oz}$, after a labour lasting 23 hours. The infant cried immediately after birth, and no injections into his body or into the umbilical cord were given. He was fed with Half-Cream National Dried Milk from the beginning as the mother (who was unmarried) wished to resume work as soon as possible and refused to breast feed.

On July 17, the infant, now 9 days old, was noticed to be irritable; his temperature was $100 \cdot 2^{\circ} \mathrm{F}$. and the scrotum was slightly swollen. Penicillin, 50,000 units, was injected intramuscularly, four-hourly for 10 days. On July 17 the temperature rose to $102 \cdot 4^{\circ} \mathrm{F}$. but the infant's general condition was remarkably good. The scrotum was grossly swollen and tense, its lower half was reddened; the swelling was fluctuant and transilluminable, and extended up to the left external inguinal ring. Aspiration, inserting a small-bore needle well above the reddened area, produced
$4 \mathrm{ml}$. of clear, straw-coloured fluid from the hydrocoele. On July 19 the infant's general condition was still good, but the temperature rose to $100 \cdot 2^{\circ} \mathrm{F}$. The lower half of the scrotum was discoloured and appeared to be about to slough. A swab was taken from this area. On July 20 the temperature was $102 \cdot 2^{\circ} \mathrm{F}$. again, and the diagnosis of scrotal gangrene was unmistakable (Fig. 1).

The pathologist reported that the swab showed necrotic pus cells, Gram-negative bacilli and Grampositive cocci, and culture gave a good growth of coliform bacilli and scanty, non-haemolytic staphylococci.

Treatment with $\frac{1}{4} \mathrm{~g}$. of sulphatriad, four-hourly, was begun and continued for seven days. Sulphathiazole powder with $1 \%$ proflavin hemisulphate was applied locally.

On July 31 the slough was separating. The infant's weight was $9 \mathrm{lb}$. On August 8 the slough had almost completely separated and there remained a scrotal ulcer, $\frac{1}{2}$ in. in diameter, covered with black, necrotic tissue centrally and with pus peripherally. On August 17, the only abnormality was a small dimple at the most dependent part of the scrotum which was everywhere covered by normal skin, but appeared to be somewhat small due to the loss of tissue. One testicle was palpable in the

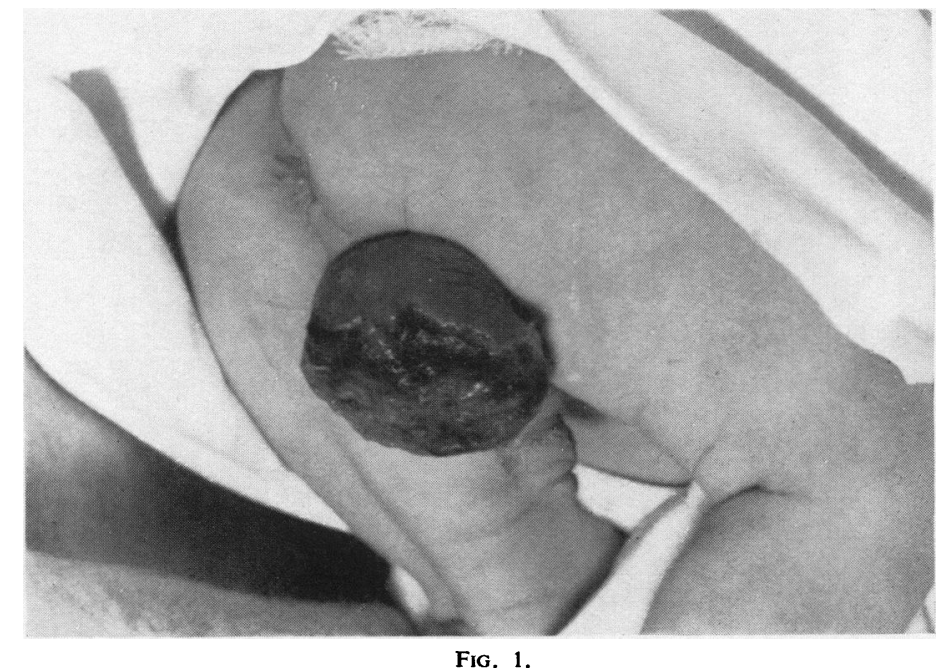

FIG. 1. 
scrotum. The infant, now 45 days old and weighing $10 \mathrm{lb} .12 \mathrm{oz}$., was discharged from hospital.

In October, 1953, the child was re-examined. He was a healthy boy, now over 4 years old, who had, according to his grandmother, never given any trouble. The scrotum appeared perfectly normal; the left testicle was descended, the right could be felt in the inguinal canal.

\section{Discussion}

Rarity of the Condition. Gangrene in the newborn is a rare condition but the number of cases reported by obstetricians and paediatricians is increasing (Brown and Smith, 1951; Delerue and Courtin, 1952; Stokes and Shumacker, 1952). Such gangrene affects, in order of frequency, the lower extremities, the upper extremities, the viscera, the gluteal region. Scrotal gangrene of the newborn would appear not to have been recorded before; Carver (1939) quotes Campbell (1922) as describing such a case in an infant 5 days old, but no such case is in fact mentioned by Campbell.

Aetiology of Idiopathic Scrotal Gangrene. Clinically the present case conformed closely to the usual descriptions of idiopathic scrotal gangrene. Barclay and Hendrick (1948) mention as characteristic features of this condition (1) sudden onset in an otherwise healthy male; (2) rapid progression of the gangrene; (3) total absence of the usual causes of gangrene; (4) extensive and relatively constant areas of gangrene, the testes, spermatic cords and inguinal regions being rarely affected; (5) a tendency for spontaneous repair.

The term idiopathic, 'a mere cloak for ignorance' (Robinson, 1946), implies that the aetiology of the condition is obscure. Two theories predominate in the modern literature. According to Mansfield (1946) in this country, and to Barclay and Hendrick (1948) in the U.S.A., idiopathic scrotal gangrene is a vascular disaster of infective origin, analogous to cavernous sinus thrombosis. The infection is not believed to have any specificity other than the existence of a pathogenic organism which causes rapid thrombosis in the vessels of the scrotal septum with consequent necrosis of the area supplied by these vessels. The fairly constant pattern of the sloughing area is thus explained on a vascular basis. This theory stresses the importance of vascular changes in this particular type of infection rather than questions the basically infective character of the condition.

Campbell (1922), Mair (1945), Robinson (1946) and others suggest that idiopathic gangrene of the scrotum is but one form of fulminating erysipelas. Mair collected 44 cases in which the bacteriology of scrotal gangrene has been investigated. In 28 of these, haemolytic streptococci were found either in pure culture or with staphylococci; only once were coliform bacilli isolated.

In the present case Bact. coli (and non-haemolytic staphylococci) were isolated from the lesion. While admitting that treatment with penicillin, which was begun two days before the swab was taken, may have eliminated haemolytic streptococci, the failure of penicillin to bring down the temperature, and the prompt response to sulphonamides, strongly suggest that the responsible organism in this case was a coliform bacillus. This may be taken as an illustration of the experience that a microorganism of usually low pathogenicity may cause in the newborn infant a serious condition which in the adult is usually produced by a different, more virulent organism. Comparable occurrences are meningitis caused by coliform bacilli and pneumonia by coliform bacilli, non-haemolytic streptococci, Staphylococcus aureus or Staphylococcus albus, in the newborn.

Aetiology of Gangrene in the Newborn. Gangrene in the newborn may be due to mechanical causes such as pressure on a particular part in utero, pressure necrosis of a prolapsed part during labour, or trauma at delivery, though the liability to gangrene of the newborn tissues is very low, as every obstetrician knows; the sometimes monstrous appearance of the face in face-presentation, or of the external genital organs in breech-presentation at the conclusion of a prolonged labour in such cases regresses to normal in a matter of hours. No such mechanical cause could have been operative in the case under discussion, as the foetus presented by the vertex, and gangrene set in several days after birth.

Mills (1949) and others after him have described arterial lesions resulting in cutaneous ulceration of the gluteal region and the lower limbs. This 'new neonatal syndrome' is strongly suspected to be due to accidental injection of nikethamide into an artery of the umbilical cord. In two of Mills' cases there was discoloration, but no ulceration, of the scrotal skin as well. This mechanism can be excluded in the present case, as no such injection was given and as the morbid process set in as late as nine days after birth.

Gangrene may be a complication of umbilical sepsis (Sheldon, 1936). Delerue and Courtin (1952) hold that infective arteriolitis may be responsible for multiple areas of gangrene associated with bronchopneumonia and other infections; the prognosis in such cases is almost always bad. There was no evidence of a generalized infection in the present case. 
A search of the literature has failed to bring to light a single case of scrotal gangrene as a spontaneous complication of hydrocoele. Only one case (Finch), dating back to 1887 , was found in which scrotal erysipelas and gangrene was described as the result of infection produced by aspirating a hydrocoele. In the present case the needle was inserted well above the reddened area in which gangrene later occurred.

Arterial spasm, with or without thrombosis or embolism, have been held responsible for gangrene of the newborn by Gross (1945), Lewis (quoted by Aird, 1949), and Stokes and Shumacker (1952). The fact that the overwhelming majority of all cases described occurred within 15 days after birth suggests some relationship to post-natal circulatory changes. (It has been suggested that intra-vascular injection of nikethamide may be followed by discharge of pituitary hormones and of adrenaline, producing vaso-constriction and ulceration in the new neonatal syndrome described by Mills.)

\section{Conclusion}

In our present state of knowledge (or rather ignorance) it is assumed that scrotal gangrene in the case presented was due to local infection with coliform bacilli which produced profound vascular changes.

\section{Summary}

A case of scrotal gangrene occurring during the neonatal period is described. The interest of this extremely rare occurrence lies in the fact that a condition usually caused in adults by haemolytic streptococci was produced in this newborn infant by coliform bacilli.

\section{REFERENCES}

Aird, I. (1949). A Companion in Surgical Studies, Edinburgh. Barclay, L. T. and Hendrick, E. B. (1948). Plast. reconstr. Surg., 3, 56. Brown, R. J. K. and Smith, S. R. N. (1951). Archives of Disease in Childhood, 26, 574.

Carver, J. (1939). Brit. J. Urol., 11, 68.

Campbell, M. F. (1922). Surg. Gynec. Obstet., 34, 780.

Delerue, J. D. and Courtin, P. (1952). Bull. Féd. Soc. Gynéc. Obstét., franc., 4, 884.

Finch, J. E. (1887). J. Minn. med. Soc., p. 86.

Gross, R. E. (1945). Amer. J. Dis. Child., 70, 61.

Lewis, T. Quoted by Aird (q.v.), p. 125.

Lewis, T. Quoted by Aird (q.v.), p.

Mair, G. B. (1945). Lancet, 1, 464.

Mills, W. G. (1949). Brit. med. J., 2, 464.

Robinson, R. G. (1946). Guy's Hosp. Rep., 95, 92.

Sheldon, W. (1936). Diseases of Infancy and Childhood. London.

Stokes, G. E. and Shumacker, H. B. (1952). Angiology, 3, 226. 